\title{
Desempenho produtivo e qualidade da carne de frangos alimentados com ração contendo óleo de linhaça
}

\author{
Karline Tikae Tani Murakami(1), Marcos Franke Pinto(1), Elisa Helena Giglio Ponsano(1) e Manoel Garcia Neto(1) \\ (1)Universidade Estadual Paulista, Departamento de Apoio, Produção e Saúde Animal, Rua Clóvis Pestana, № 793, CEP 16050-680 Araçatuba, SP. \\ E-mail: tikae@ig.com.br, mfpinto@fmva.unesp.br, elisahgp@fmva.unesp.br, mgarcia@fmva.unesp.br
}

\begin{abstract}
Resumo - O objetivo deste trabalho foi avaliar o efeito da utilização de óleo de linhaça, em substituição ao óleo de soja, sobre a produtividade e a qualidade da carne de frangos de corte de ambos os sexos. Foram utilizadas 320 aves, em um arranjo fatorial 4x2 - quatro combinações dos períodos de fornecimento de óleo de soja e óleo de linhaça e dois sexos - e quatro repetições. O desempenho produtivo foi avaliado por pesagens da ração e das aves com 1, 21, 42 dias e no momento do abate, aos 49 dias de idade. Após o abate, foi avaliado o rendimento de carcaça e sua composição: cortes, vísceras e gordura abdominal. Foram determinados os teores de lipídeos totais, umidade e colesterol da carne. A dieta contendo óleo de linhaça melhorou a qualidade nutricional da fração lipídica da carne de frango, mas prejudicou o desempenho produtivo das aves.
\end{abstract}

Termos para indexação: ácidos graxos, carcaça, dieta, lipídeos, óleo de soja.

\section{Yield performance and meat quality of broilers fed diets with linseed oil}

\begin{abstract}
The objective of this work was to assess the effect of linseed oil as a substitute to soybean oil on yield performance and meat traits of broilers of both sexes. Three hundred and twenty birds were raised in a $4 \times 2$ factorial arrangement, consisting of four receiving periods combinations of soybean oil and linseed oil and two sexes, with four replications. Yield performance was evaluated by weighting feed and broilers aging 1, 21, 42 and 49 days, when they were slaughtered. After slaughtering, carcass yield and composition in main cuts, viscera and abdominal fat were quantified. Total lipids, moisture and cholesterol contents in meat were determined. Linseed diets improved the nutritional quality of the lipid fraction of broilers meat but were harmful to broilers performance.
\end{abstract}

Index terms: fatty acids, carcass, diet, lipids, soy oil.

\section{Introdução}

A cadeia produtiva de carne de frangos é uma atividade em constante evolução (Mendes \& Saldanha, 2004). O melhoramento genético favoreceu a seleção de animais com grande potencial de ganho de peso, diminuiu a idade de abate e aumentou a produtividade (Viana et al., 2000).

Para que as modernas linhagens de frango de corte possam expressar seu potencial genético, é necessário o fornecimento de uma alimentação com alta densidade energética, e os óleos vegetais, principalmente o óleo de soja, têm sido a alternativa mais empregada para atender a essa necessidade (Almeida, 2007). A adição de óleo na ração também tem a função de fornecer ácidos graxos essenciais (Junqueira et al., 2005), melhorar a palatabilidade, diminuir a pulverulência e melhorar a absorção de pigmentos e vitaminas lipossolúveis da dieta (Braga \& Baião, 2001).
O tipo de óleo adicionado à ração pode influenciar as características relacionadas ao desempenho das aves, como consumo (López-Ferrer et al., 2001), ganho de peso (Ajuyah et al., 1991; Rodríguez et al., 2005) e conversão alimentar (Dvorin et al., 1998), bem como a composição corporal e as características da carne (Sanz et al., 1999; Crespo \& Esteve-Garcia, 2001).

A utilização de óleos vegetais, como fonte de ácidos graxos poli-insaturados (AGPI), apresenta algumas vantagens em relação à gordura animal, rica em ácidos graxos saturados (Alao \& Balnave, 1985; Gaiotto et al., 2000; López-Ferrer et al., 2001). Os óleos ricos em AGPI são absorvidos mais facilmente e, por isso, apresentam valores mais altos de energia metabolizável, o que promove melhor desempenho das aves (Dvorin et al., 1998; Gaiotto, 2004).

A deposição de gordura abdominal é um grande problema para os produtores, uma vez que parte da

Pesq. agropec. bras., Brasília, v.45, n.4, p.401-407, abr. 2010 
gordura depositada é perdida durante a evisceração da carcaça, o que resulta muitas vezes na diminuição do rendimento de carcaça. O uso de óleos fontes de AGPI é uma boa alternativa para diminuir a deposição de gordura abdominal, em razão da sua alta capacidade de oxidação (Sanz et al., 2000).

O aumento da proporção de AGPI da série ômega-3 (n-3) na ração pode ter efeito positivo na qualidade nutricional da carne de frangos, e promover a diminuição dos teores de lipídeos totais e de colesterol (Ajuyah et al., 1991; Crespo \& Esteve-Garcia, 2001), aspecto cada vez mais exigido pelos consumidores.

Embora seja uma boa fonte de AGPI, o óleo de soja contém cerca de 50 a 54\% de ácido linoléico, um AGPI da série ômega-6 (n-6) (Martin et al., 2006). Uma alternativa para aumentar a proporção de AGPI n-3 da ração é a substituição do óleo de soja por óleo de linhaça, que contém mais de $50 \%$ de ácido $\alpha$-linolênico, precursor dos ácidos graxos da série ômega 3.

O objetivo deste trabalho foi avaliar o efeito da utilização de óleo de linhaça na ração, em substituição ao óleo de soja, sobre o desempenho produtivo, o rendimento e a composição da carcaça e a qualidade nutricional da carne de frangos de corte de ambos os sexos.

\section{Material e Métodos}

Foram utilizados 320 pintos de um dia da linhagem Cobb 500, com peso médio inicial de 40,5 g, distribuídos em delineamento experimental inteiramente ao acaso, em arranjo fatorial $4 \times 2$ e quatro repetições. Os fatores avaliados foram quatro diferentes períodos em que as aves receberam dois tipos de óleo - ração formulada com óleo de soja durante todo o período experimental; ração com óleo de soja até os 21 dias e com óleo de linhaça dos 22 aos 49 dias; ração com óleo de soja até os 35 dias de idade e com óleo de linhaça dos 36 aos 49 dias e ração com óleo de linhaça durante todo o período experimental - e dois sexos.

As aves foram pesadas no início do experimento e alojadas em grupos de dez aves, em boxes de 4,60 $\mathrm{m}^{2}$ cada. Adotou-se um programa de iluminação artificial de 23 horas de luz e 1 hora de escuro, tendo-se utilizado lâmpadas fluorescentes de 32 watts. Nos primeiros dez dias de experimento, foram utilizadas campânulas elétricas com lâmpadas de 200 watts para aquecimento. A partir dos 20 dias de idade, foram utilizados exaustores e placas evaporadoras para favorecer o conforto térmico das aves. As rações experimentais foram pesadas no início do experimento e, assim como a água, fornecidas à vontade às aves durante o período experimental (Tabela 1). As rações foram formuladas de modo a atender às exigências nutricionais para as fases inicial ( 1 a 21 dias) e de crescimento e terminação (22 a 49 dias), de acordo com as exigências do National Research Council (1994). A ração inicial e a de crescimento e terminação foram formuladas, respectivamente, com 6,5 e 4,95\% de óleo de soja ou linhaça e ambas foram suplementadas com 200 ppm de vitamina E.

Para a análise de desempenho (consumo de ração, ganho de peso, peso vivo e conversão alimentar), os frangos e as rações foram pesados no $21^{\circ}, 42^{\circ}$ e no $49^{\circ}$ dia de idade.

No $49^{\circ}$ dia, três aves de cada repetição de cada tratamento foram amostradas ao acaso, identificadas com pulseiras de plástico nos pés e abatidas de acordo com as normas e procedimentos oficiais (Brasil, 1997, 1998). As aves abatidas foram depenadas, evisceradas e submetidas à avaliação de rendimento (Garcia et al., 2005). O rendimento de carcaça depenada, eviscerada, sem pés, cabeça e pescoço e a percentagem de vísceras e gordura abdominal (tecido adiposo ao redor da bolsa cloacal, proventrículo, moela e cloaca) foram calculados em relação ao peso vivo das aves no momento do embarque, após 8 horas de jejum alimentar. O peito, as coxas com sobrecoxas e as asas, todos com ossos, foram pesados e o rendimento dos cortes foi determinado em relação ao peso da carcaça depenada, eviscerada, sem pés, cabeça e pescoço, após as etapas de pré-resfriamento e gotejamento.

$\mathrm{Na}$ análise da carne, foram tomadas amostras de coxa e sobrecoxa com pele e peito sem pele, por serem as formas mais comuns de consumo. As amostras foram moídas e homogeneizadas em processador de alimentos. Os teores de umidade, lipídeos totais e colesterol foram determinados segundo a metodologia descrita pelo Instituto Adolfo Lutz (2008).

Os resultados obtidos foram submetidos à análise de variância e ao teste de Duncan a 5\% de probabilidade (Zar, 1992), pelo programa SAS (SAS Institute, 2000).

\section{Resultados e Discussão}

Embora o padrão da linhagem Cobb 500 estime um desempenho superior dos machos em relação às fêmeas para ganho de peso, consumo de ração e conversão 
alimentar (Cobb-Vantress, 2001), neste trabalho não foi observada influência do sexo no desempenho produtivo das aves (Tabela 2). Moro et al. (2005) observaram desempenho produtivo superior para os machos de quatro linhagens avaliadas. As exigências nutricionais para cada sexo são distintas. Os machos possuem demanda energética superior e por isso necessitam de uma ração com maior densidade nutricional (Rostagno, 2005). Assim, quando se trabalha com uma única ração para machos e fêmeas, como preconizado pelo National Research Council (1994), o desempenho dos machos pode ser prejudicado, principalmente na fase final do experimento, quando a demanda energética é maior e, em contrapartida, pode ocorrer maior deposição de gordura abdominal nas fêmeas, pela ingestão de energia superior à necessidade da ave.
A adição de óleo de linhaça à ração prejudicou o desempenho produtivo das aves (Tabela 2). O consumo da ração com óleo de linhaça foi menor, o que pode ser atribuído às suas características organolépticas, muito diferentes do óleo de soja (Almeida et al., 2009). Nos primeiros 21 dias de idade, observou-se menor ganho de peso nas aves alimentadas com ração contendo óleo de linhaça. O mesmo efeito foi observado em todo o período experimental. A conversão alimentar foi prejudicada pelo consumo de óleo de linhaça apenas na fase inicial, de 1 a 21 dias. Depois dessa fase, não foi observada diferença associada à dieta para esse parâmetro de desempenho. Isso se deve ao fato de que a diminuição do ganho de peso teve como causa uma correspondente diminuição de consumo.

Tabela 1. Composição percentual e calculada da ração basal para frangos de corte da linhagem Cobb nas fases inicial (1 a 21 dias) e de crescimento e terminação (22 a 49 dias).

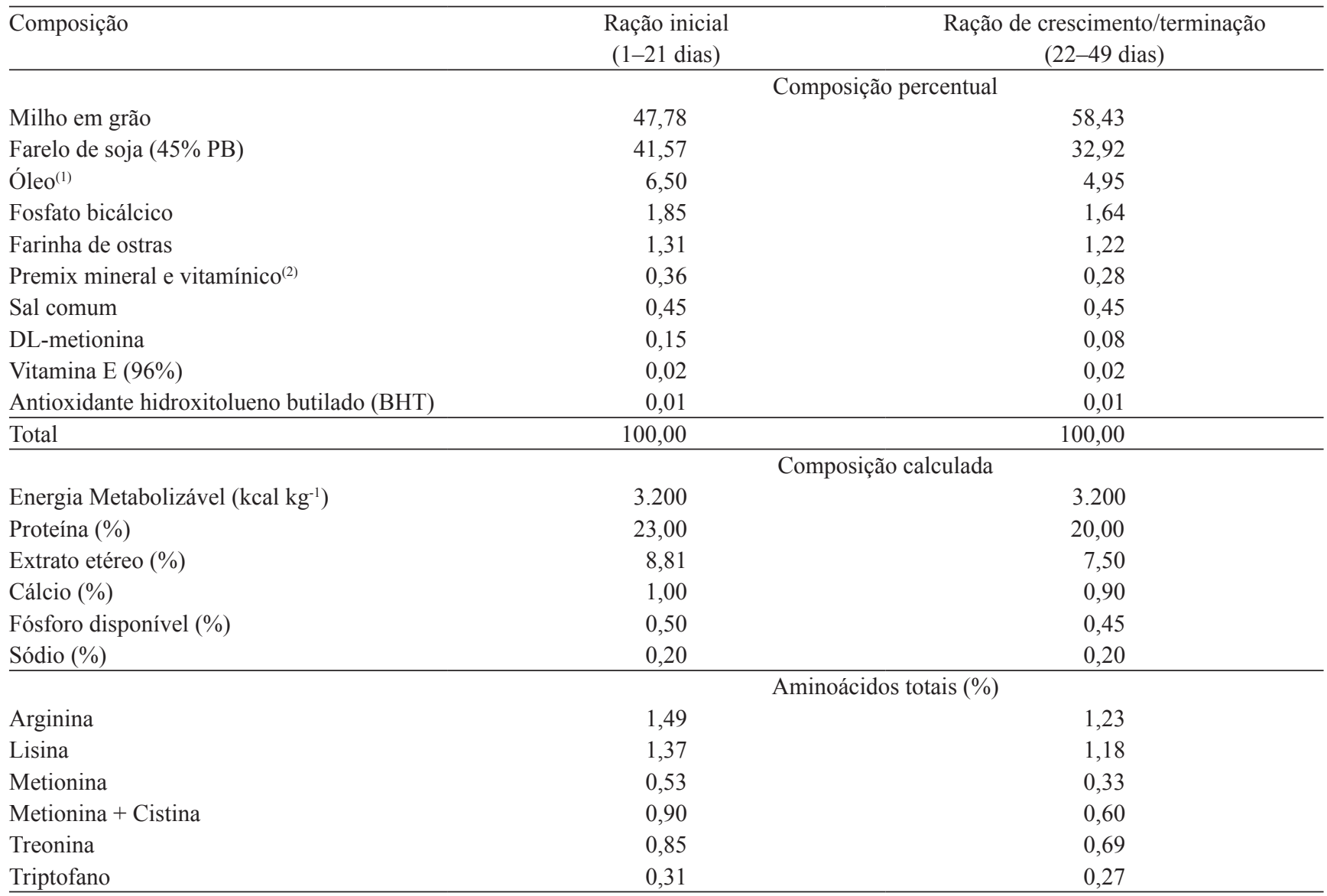

(1) Óleo de soja refinado ou óleo de linhaça bruto. ${ }^{(2)}$ Composição por kg de ração: vit. A, 8.800 UI; vit. $\mathrm{D}_{3}, 3.300$ UI; vit. $\mathrm{K}_{3}, 3,3$ mg, tiamina, 4 mg; riboflavina, $8 \mathrm{mg}$; ácido pantotênico, $15 \mathrm{mg}$; niacina, $50 \mathrm{mg}$; piridoxina, $3,3 \mathrm{mg}$; colina, $600 \mathrm{mg}$; ácido fólico, $1 \mathrm{mg}$; biotina, $200 \mu \mathrm{g}$; vit. $\mathrm{B}_{12}, 12 \mu \mathrm{g}$; antioxidante, $120 \mathrm{mg}$; manganês, $70 \mathrm{mg}$; zinco, $70 \mathrm{mg}$; ferro, $60 \mathrm{mg}$; cobre, $10 \mathrm{mg}$; iodo, $1 \mathrm{mg}$; selênio, 0,3 mg. Ração formulada conforme as exigências nutricionais do National Research Council (1994). 
O baixo desempenho de aves alimentadas com óleo de linhaça também pode estar associado ao fator antinutricional encontrado nas sementes de linhaça, denominado linatina (Allen et al., 1997), que forma um complexo com a piridoxina, e que impede a vitamina de cumprir sua função no metabolismo dos aminoácidos (Leeson et al., 2000). O principal sintoma de deficiência de piridoxina é um atraso de crescimento resultante da diminuição do apetite (Pesti et al., 2005). Como a demanda de vitamina das aves é maior na primeira fase da vida, foi nessa fase que os problemas associados ao consumo de óleo de linhaça foram observados de forma mais acentuada, afetando todos os parâmetros de desempenho avaliados.

Não houve efeito significativo do sexo ou do tipo de óleo da ração sobre as médias de rendimento de carcaça (Tabela 3). As fêmeas apresentaram maior proporção de peito que os machos. Mendes \& Patrício (2004) recomendam que a proporção de peito seja considerada na avaliação de desempenho, por ser o corte de maior valor. Assim, dependendo da demanda do mercado, a produção maior de peito pode compensar o menor desempenho produtivo das fêmeas.

As fêmeas apresentaram maior deposição de gordura abdominal (Tabela 3). Segundo Langslow \& Lewis (1974), o fato de as fêmeas apresentarem maior quantidade de adipócitos aumenta também a capacidade de depósito de gordura. Cotta \& Delpech (1990) verificaram que em geral as fêmeas apresentam taxa de deposição de gordura maior que os machos da mesma idade. Segundo Gaiotto (2004), as fêmeas possuem processos fisiológicos específicos da maturação para atividade reprodutiva, que leva ao maior acúmulo de gordura, que se acentua à medida que a idade avança, trazendo prejuízo para o rendimento da carcaça.

A deposição de gordura abdominal pode ser alterada em função do perfil de ácidos graxos da dieta. O consumo de ração contendo óleo de linhaça diminuiu a deposição de gordura abdominal em relação às aves alimentadas com soja durante todo o período (Tabela 3 ). Crespo \& Esteve-Garcia (2001) também observaram menor deposição de gordura abdominal em frangos, associada ao consumo de óleo de linhaça.

Segundo Crespo \& Esteve-Garcia (2002), a redução de gordura abdominal de aves alimentadas com dietas ricas em AGPI ocorre em razão da alta capacidade de oxidação dos ácidos graxos poli-insaturados. Além disso, os ácidos graxos poli-insaturados, especialmente os n-3, são preferencialmente depositados em fosfolipídios das membranas, diferentemente dos ácidos graxos saturados que, quando consumidos em excesso, são depositados como triglicerídeos nos tecidos gordurosos (Ponnampalam et al., 2001).

A ingestão de ração com óleo de linhaça promoveu diminuição significativa no teor de umidade da coxa com sobrecoxa (Tabela 4). Em relação ao sexo, observou-se um teor de umidade mais elevado nas amostras de coxa com sobrecoxa dos machos em relação às fêmeas. O teor de lipídeos totais dos cortes analisados não diferiu em relação ao sexo das aves. A ingestão de ração com óleo de linhaça promoveu diminuição significativa no teor de lipídeos totais da coxa com sobrecoxa.

Há divergências na literatura quanto à influência do perfil de ácidos graxos da dieta sobre a deposição de gordura nos tecidos de frangos de corte. Sanz et al. (1999)

Tabela 2. Desempenho produtivo de frangos de corte da linhagem Cobb de ambos os sexos, que receberam dietas com dois tipos de óleo em diferentes períodos ${ }^{(1)}$.

\begin{tabular}{|c|c|c|c|c|c|c|c|c|c|c|c|c|}
\hline \multirow[t]{2}{*}{ Fator } & \multicolumn{3}{|c|}{ Consumo alimentar (g) } & \multicolumn{3}{|c|}{ Ganho de peso (g) } & \multicolumn{3}{|c|}{ Conversão alimentar } & \multicolumn{3}{|c|}{ Peso médio (g) } \\
\hline & $1-21$ & $1-42$ & $1-49$ & $1-21$ & $1-42$ & $1-49$ & $1-21$ & $1-42$ & $1-49$ & 21 & 42 & 49 \\
\hline & \multicolumn{12}{|c|}{ Sexo } \\
\hline Macho & $742,60 \mathrm{a}$ & $3.585,0 \mathrm{a}$ & $4.469,1 \mathrm{a}$ & $537,2 \mathrm{a}$ & $2.183,9 \mathrm{a}$ & $2.963,5 \mathrm{a}$ & $1,33 \mathrm{a}$ & $1,73 a$ & $1,79 \mathrm{a}$ & $577,84 a$ & $2.224,6 \mathrm{a}$ & $2.996,8 \mathrm{a}$ \\
\hline \multirow[t]{2}{*}{ Fêmea } & $761,43 a$ & $3.538,0 \mathrm{a}$ & $4.442,7 \mathrm{a}$ & $552,2 \mathrm{a}$ & $2.011,6 \mathrm{a}$ & $2.791,9 \mathrm{a}$ & $1,29 \mathrm{a}$ & $1,76 \mathrm{a}$ & $1,73 \mathrm{a}$ & $592,52 \mathrm{a}$ & $2.051,90 \mathrm{a}$ & $2.832,2 \mathrm{a}$ \\
\hline & \multicolumn{12}{|c|}{ Dieta com óleo } \\
\hline $1-49 \mathrm{~S}$ & $800,8 \mathrm{a}$ & $3.823,4 \mathrm{a}$ & $4.667,9 \mathrm{a}$ & $589,5 \mathrm{a}$ & $2.207,7 \mathrm{a}$ & $2.949,4 \mathrm{a}$ & $1,30 \mathrm{a}$ & $1,75 a$ & $1,79 \mathrm{a}$ & $629,8 \mathrm{a}$ & $2.248,1 \mathrm{a}$ & $2.989,8 \mathrm{a}$ \\
\hline $1-49 \mathrm{~L}$ & $676,0 \mathrm{~b}$ & $3.425,1 \mathrm{~b}$ & $4.656,3 b$ & $479,3 b$ & $1.962,0 \mathrm{a}$ & $2.608,6 b$ & $1,33 b$ & $1,78 \mathrm{a}$ & $1,80 \mathrm{a}$ & $520,1 b$ & $2.208,1 \mathrm{a}$ & $2.649,0 \mathrm{~b}$ \\
\hline $1-21 \mathrm{~S}+22-49 \mathrm{~L}$ & $799,8 \mathrm{a}$ & $3.745,5 \mathrm{a}$ & $4.656,3 \mathrm{a}$ & $580,4 \mathrm{a}$ & $2.167,5 \mathrm{a}$ & $2.999,2 \mathrm{a}$ & $1,29 \mathrm{a}$ & $1,80 \mathrm{a}$ & $1,80 \mathrm{a}$ & $621,0 \mathrm{a}$ & $2.208,1 \mathrm{a}$ & $3.027,3 \mathrm{a}$ \\
\hline $1-35 \mathrm{~S}+36-49 \mathrm{~L}$ & $731,4 \mathrm{ab}$ & $3.251,9 \mathrm{~b}$ & $4.191,4 b$ & $530,0 \mathrm{ab}$ & $2.053,9 \mathrm{a}$ & $2.901,4 \mathrm{ab}$ & $1,32 \mathrm{a}$ & $1,64 \mathrm{a}$ & $1,66 \mathrm{a}$ & $569,7 \mathrm{ab}$ & $2.093,9 \mathrm{a}$ & $2.941,4 \mathrm{ab}$ \\
\hline $\mathrm{CV}(\%)$ & 11,48 & 8,34 & 8,29 & 13,75 & 16,21 & 9,87 & 4,74 & 15,94 & 7,76 & 12,83 & 15,91 & 9,70 \\
\hline
\end{tabular}

(1)Médias seguidas de letras distintas na coluna diferem entre si pelo teste Duncan, a 5\% de probabilidade. 1-49S: ração com óleo de soja durante todo o período experimental; 1-49L: ração com óleo de linhaça durante todo o período experimental; 1-21S + 22-49L: ração com óleo de soja até os 21 dias e óleo de linhaça dos 22 aos 49 dias; 1-35S + 36-49L: ração com óleo de soja até os 35 dias e com óleo de linhaça dos 36 aos 49 dias. 
encontraram conteúdo lipídico mais baixo no peito de frangos alimentados com dietas enriquecidas com óleos poli-insaturados. Crespo \& Esteve-Garcia (2001) relataram que o nível de gordura dietética poli-insaturada não influenciou o conteúdo de lipídios intramusculares do peito.

As amostras de coxa com sobrecoxa com pele apresentaram percentagem de lipídeos totais superior às amostras do peito sem pele. A coxa com sobrecoxa apresenta maior capacidade de depositar gordura em razão da maior necessidade de estocar energia nesses músculos, tanto para realização de atividade física de longa duração, como para isolamento térmico em períodos de frio (Ajuyah et al., 1991). Além disso, uma parcela relevante da gordura dos cortes encontra-se depositada no tecido subcutâneo.

As médias de colesterol da fração lipídica associada à carne foram menores para as aves alimentadas com óleo de linhaça, em ambos os cortes analisados (Tabela 4). Esse resultado, somado ao menor teor de lipídeos totais verificado na carne dos frangos alimentados com óleo de linhaça, demonstra que o uso desse óleo, em substituição ao óleo de soja na ração dos frangos de corte, promoveu aumento na qualidade nutricional da carne, sob o ponto de vista da saúde do consumidor. Observou-se também que as amostras de coxa com sobrecoxa, independentemente do sexo e da dieta das aves, apresentaram teor mais elevado de colesterol em comparação com o peito.

Tabela 3. Rendimento de carcaça, rendimento dos principais cortes cárneos em relação ao peso da carcaça e proporção das vísceras e gordura abdominal em relação ao peso vivo ao abate, de frangos de corte da linhagem Cobb de ambos os sexos, que receberam dietas com dois tipos de óleo em diferentes períodos ${ }^{(1)}$.

\begin{tabular}{|c|c|c|c|c|c|c|}
\hline Fator & $\begin{array}{c}\text { Rendimento } \\
\text { de carcaça }\end{array}$ & Peito & $\begin{array}{l}\text { Coxa com } \\
\text { Sobrecoxa }\end{array}$ & Asas & Vísceras & $\begin{array}{c}\text { Gordura } \\
\text { abdominal }\end{array}$ \\
\hline & \multicolumn{6}{|c|}{ Sexo } \\
\hline Macho & 72,39 & $39,08 b$ & 31,15 & 9,56 & 13,36 & $3,55 b$ \\
\hline \multirow[t]{2}{*}{ Fêmea } & 71,09 & $41,97 \mathrm{a}$ & 29,93 & 9,30 & 13,34 & $4,93 \mathrm{a}$ \\
\hline & \multicolumn{6}{|c|}{ Dieta com óleo } \\
\hline $1-49 S$ & 71,22 & 41,65 & 31,04 & 9,46 & 13,56 & $4,58 \mathrm{a}$ \\
\hline $1-49 \mathrm{~L}$ & 72,49 & 38,93 & 29,71 & 9,44 & 13,53 & $3,99 b$ \\
\hline $1-21 S+22-49 L$ & 72,20 & 41,30 & 29,82 & 9,42 & 12,77 & $4,25 \mathrm{ab}$ \\
\hline $1-35 \mathrm{~S}+36-49 \mathrm{~L}$ & 71,06 & 40,21 & 31,58 & 9,42 & 13,54 & $4,14 \mathrm{~b}$ \\
\hline CV (\%) & 9,67 & 7,38 & 6,28 & 5,65 & 8,76 & 9,49 \\
\hline
\end{tabular}

${ }^{(1)}$ Médias seguidas de letras distintas na coluna diferem entre si pelo teste Duncan, a 5\% de probabilidade. 1-49S: ração com óleo de soja durante todo o período experimental; 1-49L: ração com óleo de linhaça durante todo o período experimental; 1-21S + 22-49L: ração com óleo de soja até os 21 dias e óleo de linhaça dos 22 aos 49 dias; 1-35S + 36-49L: ração com óleo de soja até os 35 dias de idade e com óleo de linhaça dos 36 aos 49 dias.

Tabela 4. Umidade (\%), lipídeos totais (\%) e colesterol total $\left(\mathrm{mg} \mathrm{g}^{-1}\right)$ do peito sem pele e da coxa com sobrecoxa (C/S) com pele, de frangos de corte da linhagem Cobb de ambos os sexos, que receberam dietas com dois tipos de óleo em diferentes períodos $^{(1)}$.

\begin{tabular}{|c|c|c|c|c|c|c|}
\hline \multirow[t]{2}{*}{ Fator } & \multicolumn{2}{|c|}{ Umidade } & \multicolumn{2}{|c|}{ Lipídeos totais } & \multicolumn{2}{|c|}{ Colesterol total } \\
\hline & $\mathrm{C} / \mathrm{S}$ & Peito & $\mathrm{C} / \mathrm{S}$ & Peito & $\mathrm{C} / \mathrm{S}$ & Peito \\
\hline & \multicolumn{6}{|c|}{ Sexo } \\
\hline Macho & $69,82 \mathrm{a}$ & 72,70 & 15,34 & 2,27 & 83,26 & 51,33 \\
\hline \multirow[t]{2}{*}{ Fêmea } & $68,22 \mathrm{~b}$ & 72,60 & 16,03 & 2,02 & 82,47 & 50,58 \\
\hline & \multicolumn{6}{|c|}{ Dieta com óleo } \\
\hline $1-49 S$ & $68,93 \mathrm{ab}$ & 72,23 & $17,17 \mathrm{a}$ & 2,35 & $83,49 \mathrm{a}$ & $52,43 a$ \\
\hline $1-49 \mathrm{~L}$ & $68,04 \mathrm{~b}$ & 72,25 & $13,93 b$ & 2,22 & $81,74 b$ & $49,11 b$ \\
\hline $1-21 \mathrm{~S}+22-49 \mathrm{~L}$ & $68,60 \mathrm{ab}$ & 73,35 & $16,67 \mathrm{a}$ & 2,00 & $82,93 \mathrm{ab}$ & $50,92 \mathrm{ab}$ \\
\hline $1-35 \mathrm{~S}+36-49 \mathrm{~L}$ & $70,74 \mathrm{a}$ & 72,72 & $14,77 \mathrm{ab}$ & 1,97 & $83,37 \mathrm{a}$ & $51,43 \mathrm{a}$ \\
\hline$\overline{\mathrm{CV}(\%)}$ & 3,32 & 2,23 & 16,44 & 22,12 & 5,36 & 5,36 \\
\hline
\end{tabular}

${ }^{(1)}$ Médias seguidas de letras distintas na coluna diferem entre si pelo teste Duncan, a 5\% de probabilidade. 1-49S: ração com óleo de soja durante todo o período experimental; 1-49L: ração com óleo de linhaça durante todo o período experimental; 1-21S+22-49L: ração com óleo de soja até os 21 dias e óleo de linhaça dos 22 aos 49 dias; 1-35S + 36-49L: ração com óleo de soja até os 35 dias e com óleo de linhaça dos 36 aos 49 dias 


\section{Conclusão}

A substituição total do óleo de soja por óleo de linhaça bruto na ração de frangos de corte prejudica o desempenho das aves, diminui a deposição de gordura abdominal e reduz os teores de lipídeos totais e colesterol da carne.

\section{Agradecimentos}

À Fundação de Amparo à Pesquisa do Estado de São Paulo, pelo suporte financeiro.

\section{Referências}

AJUYAH, A.O.; LEE, K.H.; HARDIN, R.T.; SIM, J.S. Changes in the fatty acid composition of whole carcass and selected meat portions of broiler chicks fed full-fat oil seeds. Poultry Science, v.70, p.2304-2314, 1991.

ALAO, S.J.; BALNAVE, D. Nutritional significance of different fat sources for growing broilers. Poultry Science, v.64, p.1602-1604, 1985.

ALLEN, P.C.; DANFORTH, H.; LEVANDER, O.A. Interaction of dietary flaxseed with coccidia infections in chickens. Poultry Science, v.76, p.822-827, 1997.

ALMEIDA, A.P.S. Modificação da fração lipídica da carne de frango. 2007. 94p. Dissertação (Mestrado) - Universidade Estadual Paulista, Araçatuba.

ALMEIDA, A.P.S.; PINTO, M.F.; POLONI, L.B.; PONSANO, E.H.G.; GARCIA NETO, M. Efeito do consumo de óleo de linhaça e de vitamina E no desempenho e nas características de carcaças de frangos de corte. Arquivo Brasileiro de Medicina Veterinária e Zootecnia, v.61, p.698-705, 2009.

BRAGA, J.P.; BAIÃO, N.C. Suplementação lipídica no desempenho de aves em altas temperaturas. Cadernos Técnicos de Veterinária e Zootecnia, v.31, p.23-28, 2001.

BRASIL. Decreto $n^{\circ} 2.244$, de 5 de junho de 1997. Estabelece regulamentação da inspeção industrial e sanitária de produtos de origem animal. Diário oficial [da] República Federativa do Brasil, 4 jun. 1997. Seção 1, p.204.

BRASIL. Ministério da Agricultura, Pecuária e Abastecimento. Portaria $n^{\circ} 210$, de 10 de novembro de 1998. Aprova o regulamento técnico da inspeção tecnológica e higiênico-sanitária de carne de aves. Diário Oficial [da] República Federativa do Brasil, 26 nov. 1998. Seção 1, p.226.

COBB-VANTRESS. Manual de manejo de frangos Cobb 500: guia de manejo. São Paulo: Cobb-Vantress Brasil, 2001. 47p.

COTTA, J.T.B.; DELPECH, P. Efeitos do sexo e de diferentes níveis de proteína e lisina sobrea formação de gordura abdominal em frangos. A Hora Veterinária, v.9, p.24-26, 1990.

CRESPO, N.; ESTEVE-GARCIA, E. Dietary fatty acid profile modifies abdominal fat deposition in broiler chickens. Poultry Science, v.80, p.71-78, 2001.
CRESPO, N.; ESTEVE-GARCIA, E. Nutrient and fatty acid deposition in broilers fed different dietary fatty acid profiles. Poultry Science, v.81, p.1533-1542, 2002.

DVORIN, A.; ZOREF, Z.; MOKADY, S.; NITSAN, Z. Nutritional aspects of hydrogenated and regular soybean oil added to diets of broiler chickens. Poultry Science, v.77, p.820-825, 1998.

GAIOTTO, J.B. Determinação da energia metabolizável de gorduras e sua aplicação na formulação de dietas para frangos de corte. 2004. 82p. Tese (Doutorado) - Escola Superior de Agricultura Luiz de Queiroz, Piracicaba.

GAIOTTO, J.B.; MENTEN, J.F.M.; RACANICCI, A.M.C. Óleo de soja, óleo ácido de soja e sebo bovino como fontes de gordura em rações de frangos de corte. Revista Brasileira de Ciência Avícola, v.2, p.219-227, 2000.

GARCIA, R.G.; MENDES, A.A.; COSTA, C.; PAZ, I.C.L.A.; TAKAHASHI, S.E.; PELÍCIA， K.P.; KOMIYAMA， C.M.; QUINTEIRO, R.R. Desempenho e qualidade da carne de frangos de corte alimentados com diferentes níveis de sorgo em substituição ao milho. Arquivo Brasileiro de Medicina Veterinária e Zootecnia, v.57, p.634-643, 2005.

INSTITUTO ADOLFO LUTZ. Métodos físico-químicos para análise de alimentos. São Paulo: Instituto Adolfo Lutz, 2008. Disponível em: $<$ http://www.ial.sp.gov.br/index.php?option=com remository \&Itemid $=7 \&$ func $=$ select $\& 0 \quad$ rderby $=1 \&$ Itemid $=7>$. Acesso em: 26 ago. 2009.

JUNQUEIRA, O.M.; ANDREOTTI, M.O.; ARAÚJO, L.F.; DUARTE, K.F.; CANCHERINI, L.C.; RODRIGUES, E.A. Valor energético de algumas fontes lipídicas determinado com frangos de corte. Revista Brasileira de Zootecnia, v.34, p.2335-2339, 2005.

LANGSLOW, D.R.; LEWIS, R.J. Alterations with age in composition and lipolytic activity of adipose tissue from male and female chickens. British Poultry Science, v.15, p.267-273, 1974.

LEESON, S.; SUMMERS, J.D.; CASTON, L.J. Response of layers to dietary flaxseed according to body weight classification at maturity. Applied Poultry Science, v.9, p.297-302, 2000.

LÓPEZ-FERRER, S.; BAUCELLS, M.D.; BARROETA, A.C.; GALOBART, J.; GRASHORN, M.A. N-3 enrichment of chicken meat. 2. Use of precursors of long-chain polyunsaturated fatty acids: linseed oil. Poultry Science, v.80, p.453-761, 2001.

MARTIN, C.A.;ALMEIDA, V.V. de; RUIZ, M.R.; VISENTAINER, J.E.L.; MATSUSHITA, M.; SOUZA, N.E.; VISENTAINER, J.V. Ácidos graxos poliinsaturados ômega-3 e ômega-6: importância e ocorrência em alimentos. Revista de Nutrição de Campinas, v.19, p.761-770, 2006.

MENDES, A.A.; PATRÍCIO, I.S. Controles, registros e avaliação do desempenho de frangos de corte. In: MENDES, A.A.; NÄÄS, I. de A.; MACARI, M. (Ed.). Produção de frangos de corte. Campinas: FACTA, 2004. p.323-336.

MENDES, A.A.; SALDANHA, E.S.P.B. A cadeia produtiva da carne de aves no Brasil. In: MENDES, A.A.; NÄÄS, I. de A.; MACARI, M. (Ed.). Produção de frangos de corte. Campinas: FACTA, 2004. p.1-22.

MORO, D.N.; ZANELLA, I.; FIGUEIREDO, E.A.P. de; SILVA, J.H.S. da. Desempenho produtivo de quatro linhagens de frangos de corte. Ciência Rural, v.35, p.446-449, 2005. 
NATIONAL RESEARCH COUNCIL. Nutrient requirements of poultry. 9.ed. Washington: National Academy Press, 1994. 155p.

PESTI, G.M.; BAKALLI, R.I.; DRIVER, J.P.; ATENCIO, A.; FOSTER, E.H. Poultry nutrition and feeding: a textbook. Victoria: Trafford, 2005. 449p.

PONNAMPALAM, E.N.; SINCLAIR, A.J.; EGAN, A.R.; BLAKELEY, S.J.; LI, D.; LEURY, B.J. Effect of dietary modification of muscle long chain n-3 fatty acid on plasma insulin and lipid metabolites, carcass traits, and fat deposition in lambs. Journal of Animal Science, v.79, p.895-903, 2001.

RODRÍGUEZ, M.L.; ORTIZ, L.T.; ALZUETA, C.; REBOLE, A.; TREVINO, J. Nutritive value of high-oleic acid sunflower seed for broiler chickens. Poultry Science, v.84, p.395-402, 2005.

ROSTAGNO, H.S. (Ed.). Tabelas brasileiras para aves e suínos: composição de alimentos e exigências nutricionais. 2.ed. Viçosa: UFV, 2005. 186p.
SANZ, M.; FLORES, A.; DE AYALA, P.P.; LOPEZ-BOTE, C.J. Higher lipid accumulation in broilers fed on saturated fats than in those fed on unsaturated fats. British Poultry Science, v.40, p.95-101, 1999.

SANZ, M.; LOPEZ-BOTE, C.J.; MENOYO, D.; BAUTISTA, J.M. Abdominal fat deposition and fatty acid synthesis are lower and $\beta$-oxidation is higher in broiler chickens fed diets containing unsaturated rather than saturated fat. Journal of Nutrition, v.130, p.3034-3037, 2000.

SAS INSTITUTE. SAS/STAT software: changes and enhancement through, release 8.2. Cary: SAS Institute, 2000.

VIANA, C.F.A.; SILVA, M. de A. e; PIRES, A.V.; FONSECA, R. da.; SOARES. P.R. Influência de grupos genéticos e de níveis de energia sobre características de carcaça de frangos de corte. Revista Brasileira de Zootecnia, v.29, p.1067-1073, 2000.

ZAR, J.H. Biostatistical analysis. $4^{\text {th }}$ ed. New Jersey: Prentice-Hall, 1992. 930p.

$\overline{\text { Recebido em } 27 \text { de agosto de } 2009 \text { e aprovado em } 26 \text { de março de } 2010}$ 